\title{
"Ethical competence training for members on clinical ethics committees (CEC): experiences from Denmark"
}

\author{
Jeanette Bresson Ladegaard Knox ${ }^{1,2,3,4}$
}

Published online: 22 May 2017

(C) Springer International Publishing AG 2017

\begin{abstract}
To address the moral questions in patient care and medical practice, Danish hospitals are starting to solicit clinical ethics committees (CEC). As in other places around the world, CECs in Denmark is an interdisciplinary group that includes physicians, nurses, social workers, psychologists, lawyers, chaplains, and sometimes lay persons. Due to their distinct professional background, members are largely untrained in concepts, skills and the language of moral philosophy and ethical reasoning. The absence of appropriate competencies makes it challenging for members to identify, analyze and resolve lingering moral quandaries. Thus, the creation of CECs in Denmark has raised the question of qualifications for those who serve on a committee. When the Danish Society of Clinical Ethics was formed in 2012, it was therefore at the forefront of its agenda to establish a training program that would offer valuable contributions to the ethical aspect of medical decision making and to serve as an important resource for health care providers, patients and their families. This article describes the history, development and preliminary results of the current training program as well as reflects on future ideas for ethics education for Danish CECs and health care providers at large.
\end{abstract}

Keywords Ethics training Education $\cdot$ Clinical ethics committees/consultation $\cdot$ Medical ethics

Jeanette Bresson Ladegaard Knox

knox@sund.ku.dk

1 Department of Public Health, University of Copenhagen, Øster Farimagsgade 5, building 10, 1014 Copenhagen K, Denmark

2 Danish Society for Philosophical Practice, Copenhagen, Denmark

3 Danish Society for Clinical Ethics, Copenhagen, Denmark

4 Clinical Ethics Committee for Pediatrics, The Kingdom Hospital in Copenhagen, Copenhagen, Denmark 


\section{Background}

Ethics began breaking out of "the theoretical domains of philosophy" (Gunning and Holm 2005, p. 3) and enter the medical field in the early 1970s. The rapid growth of biotechnology and medical know-how spurred an array of moral questions. The assisted reproductive technologies of the 1980s were awarded much public attention that eventually led lawmakers around the world to the creation of National Ethics Councils. In Denmark, such a Council was formed in 1987. In the area of patient care, clinical ethics committees (CEC) slowly emerged in the US in the 1970s where they are often called hospital or healthcare ethics committees (HEC) (Rosner 1985). Mandated in 1992 by the Joint Commission on Accreditation of Healthcare Organizations (JCAHO), HECs now exist in most hospitals in the US. A decade later CECs surfaced in Europe (Slowther et al. 2011). Some countries require by law hospitals to have CECs, as for example in Norway (Førde and Hansen 2009), Belgium (Meulenbergs et al. 2005) and Croatia (Borovečki et al. 2006). In the Netherlands, CECs have been a feature of hospitals and nursing homes since the 1980s (Van der Kloot Meijburg and Ter Meulen 2001).

With the rise of CECs, questions of appropriate educational programs follow. Workshops, seminars, short courses, fellowships and graduate programs in medical and clinical ethics around the world are responses to the need for ethics training that can provide a knowledge base and skill set. Several seminal books have been published to supplement the need of CEC members for greater insight in the field of ethics and committee work (e.g. Fletcher et al. 1995; Aulisio et al. 2003; Hester 2007; Hester and Schonfeld 2012). National guidelines have been developed to frame clinical ethics practice. The American Society for Bioethics and Humanities' (ASBH) detailed core competencies for ethics consultation in health care in its original report from 1998 on 'Core Competencies for Health Care Ethics Consultation', now in its second edition (ASBH Core Competencies Update Task Force 2011). Similar guidelines are seen in the UK, Canada, France (Gaucher et al. 2013). In many countries, ethics education is conducted or supervised by medical ethics centers that are most often based at a university's faculty of medicine. The Center for Medical Ethics at the University of Oslo has been granted the national responsibility to coordinate the Norwegian CECs and build ethics competence for its members (Førde and Pedersen 2011). Similarly, the Ethox Center at the University of Oxford in the UK provides ethics courses and workshops specifically intended for committee members.

Services of ethics committees in health care are nowadays commonplace practices around the world (Varelius 2008). Services are provided to assist in identifying, analyzing and resolving complex moral questions in clinical practice. Denmark has been late in attending to and developing clinical ethics and establishing ethics committees, and the country does not have an organized and elaborate platform for ethics education for clinical ethics consultation and CEC work.

The first Danish CEC was created in 2003 by chief physician Henri Goldstein at Køge hospital. Unfortunately, it was short lived as Goldstein left his position a couple of years after forming the committee and, as a consequence, it sadly quickly dissolved. The following year saw the rise of a CEC in Frederiksberg Hospital that exists today though it has gone through many changes and also been dormant at times. The two mentioned CECs led such a clandestine life that Lebeer in an article on CEC in Europe 
concluded in 2005 that Denmark did not have any CEC at all (Lebeer 2005, p. 66). By 2008, one vociferous committee emerged in Northern Jutland at the University Hospital of Aalborg. This committee was joined in 2009 by the first CEC within psychiatry for the region of Southern Denmark. Both CECs exist today.

A joint venture between the Danish Doctor's Union and the Danish Nurses Union resulted in 2007 in a proposal for the establishment of one CEC in each of the five regions in Denmark. The proposal was sent to the minister of Health, Lars Lykke Rasmussen, who eventually rejected the proposal. By the late 2000s individual hospital health care providers had initiated their own CEC and by 2010 there were recorded 6 CECs nationwide. Though Denmark does not have a steady number of CECs as some begin only to close down a couple of years later, there are at present 14 registered CECs. It is a far cry from the formally structured effort to organize, develop and support CECs as we have seen it in the US, the UK, Norway, or the Netherlands.

In 2011, a group of health care professionals met with the idea of establishing a national umbrella to serve the interests of the already existing CECs, to help create new ones and to act as an advocate for clinical ethics in general. This network of passionate supporters of clinical ethics was the precursor of what was to become the Danish Society of Clinical Ethics (DASKET: Dansk Selskab for Klinisk Etik) which was created in June 2012 with a 7 member board consisting of three physicians, a nurse, a midwife, a historian of ideas with previous long-standing experience as a nurse and a philosopher with experience as a clinical ethicist (author of this article). The society is comparable to but not identical with the Clinical Ethics Network which is a network of CECs throughout the UK.

\section{Structure and content of training program: Module 1}

In the fall of 2012, the Board of DASKET convened to unfold its visions for clinical ethics in Denmark and to identify the scope of its priorities and how a Society could support the existing and emerging CECs. Ethics education of committees was a high priority and the topic of ethics education programs was thoroughly discussed. Decision was made to have the historian of ideas/nurse and myself devise an intensive course. I was subsequently designated to be responsible for the course and propose structure and content. We would teach the course together except for one lecture on 'medical ethics and law' that was taught by an invited teacher. The course design was finished in the spring of 2013 and was offered for the first time in the fall of 2013.

The ethics training program is split into two modules: Module 1 and Module 2. The second one builds on to the first one. Both modules are offered once a year, usually in the fall. Module 1 is a two day intensive course followed one year later by a one day follow-up course (Module 2). There is a manageable reading load assigned to Module 1. One reason for opting for this design is the fact that three days are easier to work into an already busy schedule than a whole week or a semester long course. Another reason is the limited financial resources given to CECs. Some committees receive financial support of a varying amount, others receive nothing.

Considering the limited time available in a three-day course, the challenge was how to properly introduce participants not familiar with the language of moral philosophy and ethical reasoning. One particular inspiration to Module 1 came from the week-long 
course in bioethics that was offered by the Kennedy Institute of Ethics at Georgetown University in Washington D.C., USA, for almost 40 years. The course proposed a suitable format and manageable content for our three-day intensive course intended for CEC members. ASBH's report 'Core Competencies for Health Care Ethics Consultation' (ASBH, 2011) was also an important resource of information on knowledge base and skill set.

Learning objectives for Module 1 are divided into five sections. They have remained the same throughout. The five sections depict various aspects covered by the course content: First, participants will become familiar with classic moral theories and fundamental principles in medical ethics; secondly, they will become familiar with ethical reasoning and argumentation; thirdly, they will become capable of identifying and analyzing the ethical dimensions in a case by the help of standardized and systematic models of ethical reflection; fourthly, they will gain insight into the work and challenges of a CEC; and lastly, they will become familiar with relevant national law and policies and relevant international conventions pertained to medical ethics in a hospital setting.

As most health care workers are untutored in clinical ethics, the course begins with a historical view of the field, both of medical ethics and CECs. The most common structure and purpose of CECs and basic qualifications for committee work are described in order to understand the tradition in which they take part as members of a CEC. International and national experiences with clinical ethics consultation and committee work are also presented. In view of the learning objectives, Module 1 is primarily designed to familiarize members of a clinical ethics committee to moral theory and medical ethics as related to committee work. To solidify a theoretical background, the classic moral philosophies of deontology, utilitarianism and virtue ethics are introduced followed by the American and European ethical principles within the medical ethics. The course also covers basic components of ethical reasoning and argumentation. Suggestions as to how to apply theory to practice are presented and discussed. Based on experiences from the Netherlands (Molewijk et al. 2008, Weidema et al. 2012) and from Norway (Førde and Vandvik 2005), participants learn to work with two reflection models to structure and direct their analysis of ethics cases.

Intentionally, the course moves back and forth between theory and practice. 'Practice' does not refer to the actual issues and questions of CECs as much as to the practice of theory on cases. During the two day course the participants analyze several of their own cases in different groups to imitate CEC case work. All cases have to be sent to the teachers beforehand to give both teachers time to study them and to give the course responsible time to create groups in advance. The ethical questions raised in their cases cover common issues such as coercion, autonomy, various aspects of the patient-healthcare provider relationship (confidentiality, empathy, consent, etc.) and setting boundaries for when to withhold /withdraw treatment. Though the participants work on questions that stem from their own CECs, the primary aim is not resolving these questions in class but to exercise conceptual tools for better analyzing the ethical complexity of cases.

Course material is sent electronically before the course and consist of a couple of introductory texts on medical ethics and clinical ethics consultation along with two reflection models, one developed by the Center for Medical Ethics at the University of Oslo (i.e. the SME Model, formerly known as the Six-Step Model) and the other by the 
author of this article based on her work at the NICU in the Kingdom Hospital in Copenhagen (Knox 2014). The participants learn about the normative backdrop and procedural steps of each method in class along with the differences between the models in structuring and facilitating moral deliberation.

Role play is widely used within medical training as an education method to develop communication and interpersonal skills (Nestel and Tierney 2007). In role play, students get a chance to rehearse situations in preparation for future scenarios with the hope of improving specific skills. The role play in Module 1 is set up as to simulate a situation between a patient and a doctor. An actor is hired to presume the role of a patient. One teacher acts as the physician and the class represents a CEC. After the enactment the class/CEC discusses the case. The class is instructed to use what they have acquired so far to assist in their approach to and analysis of the case, i.e. identifying the kind of moral issue at hand, the moral knowledge to lean on and the best suited reflective model to use. The right model to select depends on the kind of moral issue at hand. This includes considering whether the issue is a question, a dilemma or a theme.

During the two-day seminar, pearls and perils in ethics consultation are examined and participants are informed of the most common ones listed by the American Society for Bioethics and Humanities (Carrese 2012). By addressing these known pearls and perils, local pearls and perils can be recognized to better prepare CEC members when addressing actual cases in their committee.

Location for the course is a conference site in the middle of Denmark. The site was chosen to enable a fair transportation time for participants coming from all corners of the country. An exception is made if a local committee buys the course, as what happened in 2016. In that event, the location is moved to the home hospital of the CEC.

\section{Implementation of module 1}

Module 1 has been carried out three times in 2013, 2014 and 2016. In 2015, we had to cancel the course due to lack of enrolled participants. Our minimum requirement of 12 students had not been met. In 2013 there were 25 participants in the class. In 2014 the number was 18 and we had 14 in the 2016 class. Module 2 has been offered twice in 2014 and 2015 and carried out once in 2015. We had to cancel the course in 2014 due to lack of participants. Module 2 that took place in 2015 consisted of participants who had completed the Module 1 in either 2013 or 2014.

In 2013 and 2014 participants came from committees all over Denmark. It had been announced on the website of the Society. Both years, Module 1 was held at a hotel/ conference center located in central Denmark. In 2016 a local committee decided to buy the course for all its members. The course was consequently held at one of the hospital that houses the committee.

Not all hospitals and medical staff have been receptive to the implementation of clinical ethics in Denmark. Most committees can testify to the arduous work involved in setting up a committee and sustaining it as well as seeking institutional approval and financial backing. CECs need moral and financial support from the hospital organization to exist and progress (Schick and Moore 1998; Førde and Pedersen 2011). Reaching the intended audience, i.e. primarily members of CECs, proved at first to 
be fairly easy. However, in light of the fact that there are only about a dozen CECs in Denmark and that most of them are on a very limited budget, it has become increasingly difficult to recruit participants.

Some changes have been made since the launch of Module 1. We used role play the first two years. Though it predominately got positive feedback, we dropped it in 2016 to reduce expenses. In 2014 and 2016 we have practiced a walk-and-talk segment. The second day of the course begins with a brief introduction to a case. The participants are asked to analyze the case while walking in small groups of 3-4 using the material they have been introduced to the previous day. After the 30-40 min walk, they return to discuss their findings in the class.

At the end of the two day course, we encourage the participants to commit to selfeducation, for example by following relevant debates and reading new publications that eventually can be shared in the committee. We also introduce the participants to Module 2. A certificate of attendance is issued upon request.

\section{Evaluation of module 1: Some preliminary results}

All participants are asked to fill out an open-ended, anonymous questionnaire at the end of the course. The questionnaire consists of 10 questions. This questionnaire serves as an evaluation tool and is sent electronically to participants. The responses are sent to the secretary of DASKET who sends them on to me and my co-teacher to preserve their anonymity. For those participants who prefer a handwritten version, this is provided in class. They can either mail their responses to the secretary of DASKET or, if desired, hand them to one of the teachers. The questionnaire has been identical since the course was offered (see Table 1). The questionnaire was developed by the first Board of DASKET and was based on a draft that I had designed. After all Board members had studied the questions and the set-up of the questionnaire, they sent their comments and suggestions to me and my co-teacher. The questionnaire was subsequently revised and sent around to Board members for final approval.

\section{Table 1}

Evaluation Questionaire

1. How would you assess the course as a whole?

2. Did the course live up to the announced learning goals?

3. In what way has the course provided knowledge and tools for your work in a CEC?

4. What has been good?

5. What can be improved?

6. How would you assess the teachers (knowledge, presentation, contact, engagement)?

7. How would you assess your own contribution in class?

8. What did you think of the role play?

9. What did you think of the course location (rooms, sound and lighting conditions, equipment, catering accommodation)?

10. Additional comments 
Response rate has been low. On average only half of the participants filled it out. One explanation for the low response rate could be that most participants verbally aired their thoughts on the course on the last day of the course either in class or to one or both of the teachers. Evaluations are read and discussed by the two teachers. An oral account of the course process, including questionnaire responses, is presented at the following Board Meeting within the Society of Clinical Ethics. All members receive the responses that are handed in and these are assessed at the meeting by all members. Course structure, feedback and potential ameliorations are discussed and suggestions made.

In the weeks following the Board meeting, we the teachers discuss possible changes and/or modifications in the course design and course curriculum. If changes and/ modifications are deemed necessary based on the discussion at the Board meeting, these are written in immediately.

The evaluations reveal, in general, a profuse satisfaction with the course. This sentiment is supported by oral statements at the end of the course. People appreciated the balanced interaction between theory and practice and the focus on actual case analysis in groups. They spoke of the revelation that committee work is not to achieve a final answer or solutions but rather to unfold a case and, as such, help health care providers qualify a decision or improve an understanding. The use of their own cases to go through reflective models along with the conceptual language of medical ethics was highlighted by participants as critical to the course and highly relevant for their committee work. The role play was viewed as a thought-provoking, enlightening and poignant way of portraying an ethically complicated situation. People responded favorably to the walk-talk segment stating that it combines a relaxed attitude to absorbing complex material, yet containing a specific focus in mind while enjoying the actual act of walking. It was a way to calmly digest abstract ideas that are unlike their practical daily routines in the hospital.

Many participants also pointed to the learning advantage of meeting other committee members from other parts of the country and to exchange and discuss experiences regarding committee formation, organization and visibility as well as case load and case analysis as a great strength for the course.

Furthermore, the evaluations illustrate the need for additional ethics training to improve and appropriately equip CEC members for the task of ethical analysis and guidance. Repeatedly, the participants pointed to the limits of a two-day course in terms of acquiring complex knowledge and skill set and the application challenges involved.

\section{Follow-up course: Module 2}

Module 2 is a continuation of Module 1 and takes place one year after Module 1 for members who have finished Module 1. Unlike the first training program, Module 2 is a one-day course. The reason for the interim between the two courses is to give the CECs a chance to work with the conceptual tools, ethical reasoning and reflective models that they learned about in the first course. The idea behind the Module 2 is to address the experiences that arose after the Module 1. The one-day seminar is tailored to the participants' topics and challenges that they have encountered during the year. Module 2 is, of course, voluntary. Not all participants from module 1 attend module 2 though we encourage participants to consider the two modules as interconnected. 
Participants are asked to write a small report of a page long. The report intends to describe their experiences using a structured model for ethical reflection and lists specific needs for further knowledge, literature, and training they may have as well as what they would like the course to address in particular. In the report, they are asked to reflect on: How has it been to incorporate moral theoretical positions or principles of case-analysis? What challenges have you encountered using the ethical reflective models that were introduced in the first course? What would you like to know more about or have repeated? What would you like to get better at? What has worked well? We recommend the participants to discuss the report in their committee and that some consensus is reached for the final wording of the report.

The reports that we have hitherto received have several common denominators. One common feature concerns discrepancies between management's ambition for the committee and the committee itself. Others concern meeting frequency and the challenge of becoming more visible within hospital walls. Most members, if not all, regret not getting more cases referred to them. In case analysis, the reports state that members experience great support in the analytical models that were introduced in the course. Nonetheless, they still express the need for further ethics training and also underline the need for dialogue facilitation building. Guiding a committee through a case appeared harder than expected. The reports also convey the challenge of applying the conceptual framework of medical ethics to concrete cases and keep the ethical focus in the reflective dialogue.

A program for the day is put together when the reports have been read and discussed by both teachers. This program is sent to the participants. The program may vary from time to time where module 1 has largely remained identical over the years.

\section{Looking ahead: Some reflections}

Module 1 and 2 comprise but a three-day course in medical and clinical ethics. Needless to say with the time constraint of the modules that they can only hope to give a glimpse of the moral theories, principles and ethical reasoning and language employed by committee members. The limited scope of the courses reveals the need for further courses. In order to strengthen the competencies of health care professionals and the quality of education in the field as well as to continue to build on the knowledge acquired and the skills learnt, it is desirable that Danish universities in the future take on the task of facilitating and coordinating ethics education programs at an academic level as seen elsewhere in the world. In Norway, the Centre for Medical Ethics at the University of Oslo offers courses for members of CECs as does the British Ethox Centre at the Institute of Health Sciences in Oxford. Master and $\mathrm{PhD}$ programs in medical and clinical ethics are today offered at a wide range of universities around the world. One of the benefits of these academic programs is also that they are most often directly linked to university hospitals or offered through their medical schools. The link strengthens the interplay in clinical ethics between theory and practice. I am presently working with colleagues from the University of Copenhagen in creating a Master of Medical Ethics with special attention given to its clinical aspect. If we are successful, it will be the first of its kind in Denmark. 
Though theories and principles are considered highly valuable to the analysis of cases, their exact contributions are still hard to identify (Magelssen et al. 2016) and they are entirely obsolete if divorced from medical practice (The Lancet 1997). In the development of new, longer and more in-depth courses it will be necessary to more thoroughly consider and practice how to apply the knowledge of moral philosophy in a clinical setting. Workshops that target substantive issues faced by CEDs, such as when to withhold treatment or when coercion is helping or harming the patient, would also be relevant to offer. A direct application where one theory is glued on to reality will quickly meet a dead end as one is abstract and rational and the other concrete and messy. In addition, ethical deliberation is not guaranteed by knowledge of moral theories alone. Character and virtue development is equally important as clearly stated in ASBH's report on core competencies for ethics consultation (ASBH, 2011) but the challenge of teaching it remains a point of debate as noted by prominent bioethicists (Singer et al. 2001; see also Glover and Nelson 2003, p. 55).

In teaching the course, my teaching partner and I have come to acknowledge the role of dialogue facilitation as a principal component in ethical deliberation. The facilitator structures and guides the reflective process through the moral morass embedded in most cases put before a CEC. Steering a moral case analysis is not an easy task but it is a skill that can be learnt. Combining a Socratic style of dialogue with moral deliberation has been expounded by many Dutch clinical ethicists (Birnbache 1999; Steinkamp and Gordijn 2003; Stolper et al. 2015). Socratic dialogue targets two key aspects of CEC work: content and communication. Socratic dialogue focuses on building a partnership of thoughts and ideas among its members. It forces bridges between fractions instead of maintaining divides as its aim is unfold as many perspectives of a moral complexity as possible. It calls for an open, inquisitive exploration of the ethical issues that are relevant to the case at hand where members take a distanced yet engaged look at an issue. This is a form of dialogue that calls upon each member to "listen without resistance" (Isaacs 2008, p. 101). In other words, listeners refrain from reacting spontaneously to what is said and suspend their personal and/or professional judgments on the topic. It fortifies the reflective process within CEC as a collaborative effort.

Another potential course concerns narrative ethics. Narrative ethics has branched out of narrative medicine as coined by Rita Charon (Charon 2008). Settling into classifying cases by use of theories, principles and reflective models can stifle the narrative voice within a case. Attentive listening to narratives recognizes the full life-framed effects of illness on patients and can alert the CEC members and ethics consultants to patients' muddled illness experience that eludes any neatly organized narrative template (Brockmeier 2008; see also Goldie 2012).

Narrative ethics is a dialogical endeavor (Frank 2014). In this sense, it is similar to Socratic dialogue. When serious illness strikes, stories that previously carried weight and truth offer little direction to patients which can impact their decision making. Living through a chaos story, they may experience "the absence of narrative order" (Frank 1995, p. 97). Ethics consultants and CEC members can help the patients' new story emerge and help the health care professionals become more attuned to and reflective of patients' illness experience by learning 'close reading' (Charon 2008). Close reading can provide an understanding of how patients, relatives, health care professionals are "cast to play parts in others' stories and [...] how they are cast will affect subsequent interpretations of how they act" (Frank 2014, p. S18). 
Building dialogical competencies through Socrates and story-telling on top of foundational knowledge of moral theories and principles, ethical reasoning and case analysis can ensure a firm basis for training of CEC members.

In a time where evidence based medicine and efficient statistical tools reign in health care, CEC can support a humanistic approach to patient care and protect the ethical decision making aspect of medical practice. Diagnostic manuals do not disentangle the complex texture of ethical issues. Other skills and a different knowledge are needed. In Denmark at present, no national or regional directive guides the selection process for committee members, the procedure for ethics consultation, the written recording of consultations or the level of ethics training. It is in the interest of patients, their relatives and health care workers alike to solidify the legitimate authority of CECs in Danish hospitals by securing transparency, accountability and the quality standard of its service. Ethics education is an undeniable prerequisite in this effort.

Acknowledgements My sincere thanks go to my teaching partner Anne Marie Enderlein for her very useful comments.

\section{Compliance with ethical standards}

Conflict of interest None to declare.

\section{References}

ASBH Core Competencies Update Task Force. 2011. Core competencies for health care ethics consultation: The report of the American Society for Bioethics and Humanities. Glenview: American Society for Bioethics and Humanities (ASBH).

Aulisio, Mark P, Robert M Arnold, and Stuart J Youngner. 2003. Ethics consultation: From theory to practice. Baltimore: the Johns Hopkins University Press.

Birnbache, Dieter. 1999. The Socratic method in teaching medical ethics: Potentials and limitations. Med Health Care Philos 2 (3): 219-224.

Borovečki, Ana, Henk Ten Have, and Stjepan Orešković. 2006. Education of ethics committee members: Experiences from Croatia. J Med Ethics 32 (3): 138-142.

Brockmeier, Jens. 2008. Language, experience, and the "traumatic gap": How to talk about 9/11. Health, illness and culture: Broken narrative: 16-35.

Carrese, Joseph A. 2012. HCEC pearls and pitfalls. The Journal of clinical ethics 23 (3): 234-240.

Charon, Rita. 2008. Narrative medicine: Honoring the stories of illness. Oxford: Oxford University Press.

Fletcher, John C, Charles A. Hite, Paul A. Lombardo, and Mary Faith Marshall. 1995. Introduction to clinical ethics. Frederick: University Publishing Group.

Førde, Reidun, and Thor Willy Ruud Hansen. 2009. Involving patients and relatives in a Norwegian clinical ethics committee: What have we learned? Clinical Ethics 4 (3): 125-130.

Førde, Reidun, and Reidar Pedersen. 2011. Clinical ethics committees in Norway: What do they do, and does it make a difference? Camb Q Healthc Ethics 20 (03): 389-395.

Førde, Reidun, and I.H. Vandvik. 2005. Clinical ethics, information, and communication: Review of 31 cases from a clinical ethics committee. J Med Ethics 31 (2): 73-77.

Frank, Arthur. 1995. The wounded storyteller: Body, illness. Chicago: the University of Chicago Press.

Frank, Arthur W. 2014. Narrative ethics as dialogical story-telling. Hastings Cent Rep 44 (s1): S16-S20.

Gaucher, Nathalie, John Lantos, and Antoine Payot. 2013. How do national guidelines frame clinical ethics practice? A comparative analysis of guidelines from the US, the UK, Canada and France. Soc Sci Med 85: 74-78. 
Glover, Jacqueline J., and William Nelson. 2003. Innovative Educational Programs: A Necessary First Step Toward Improving Quality in Ethics Consultation. In Ethics Consultation: From theory to practice, ed. Mark P. Aulisio, Robert M. Arnold, and Stuart J. Youngner. Baltimore: The Johns Hopkins University Press.

Goldie, Peter. 2012. The mess inside: Narrative, emotion, and the mind. Oxford: Oxford University Press.

Gunning, Jennifer, and Soren Holm. 2005. Ethics. Volume I: Law and Society. Aldershot, England/Burlington, VT: Ashgate, 2005.

Hester, Micah D. 2007. Ethics by committee: A textbook on consultation, organization, and education for hospital ethics committees. Lanham: Rowman \& Littlefield Publishers.

Hester, D. Micah, and Toby Schonfeld. 2012. Guidance for healthcare ethics committees. Cambridge University Press.

Isaacs, William. 2008. Dialogue: The art of thinking together. Crown Business.

Knox, Jeanette Bresson Ladegaard. 2014. The 4C model: A reflective tool for the analysis of ethical cases at the neonatal intensive-care unit. Clinical Ethics 9 (4): 120-126.

Lebeer, Guy. 2005. Clinical ethics committees in Europe: Assistance in Medicial decisions, fora democratic debates, or bodies to monitor basic rights. In Ethics, Law, and Society, ed. Jennifer Gunning and Søren Holm, vol. vol. 1. Burlington: Ashgate Publishing.

Magelssen, Morten, Reidar Pedersen, and Reidun Førde. 2016. Four roles of ethical theory in clinical ethics consultation. Am J Bioeth 16 (9): 26-33.

Meulenbergs, T., J. Vermylen, and P.T. Schotsmans. 2005. The current state of clinical ethics and healthcare ethics committees in Belgium. J Med Ethics 31 (6): 318-321. doi:10.1136/jme.2003.006924.

Molewijk, A.C., T. Abma, M. Stolper, and G. Widdershoven. 2008. Teaching ethics in the clinic. The theory and practice of moral case deliberation. Journal of Medical Ethics 34 (2): 120-124

Nestel, Debra, and Tanya Tierney. 2007. Role-play for medical students learning about communication: Guidelines for maximising benefits. BMC medical education 7 (1): 3.

Rosner, Fred. 1985. Hospital medical ethics committees: A review of their development. JAMA 253 (18): 2693-2697.

Schick, Ida Critelli, and Fache Sally Moore. 1998. Ethics committees identify four key factors for success. In HEC Forum: Springer (10): 75-85.

Singer, Peter A., Edmund D. Pellegrino, and Mark Siegler. 2001. Clinical ethics revisited. BMC Medical Ethics 2 (1): 1. doi:10.1186/1472-6939-2-1.

Slowther, Anne Marie, Leah McClimans, and Charlotte Price. 2011. Development of clinical ethics services in the UK: a national survey. Journal of medical ethics:medethics-2011-100173.

Steinkamp, Norbert, and Bert Gordijn. 2003. Ethical case deliberation on the ward. A comparison of four methods. Med Health Care Philos 6 (3): 235-246.

Stolper, Margreet, Bert Molewijk, and Guy Widdershoven. 2015. Learning by doing. Training health care professionals to become facilitator of moral case deliberation. In HEC Forum: Springer (27): 47-59.

The Lancet. 1997. The ethics industry. The Lancet 350 (9082): 897. doi:10.1016/S0140-6736(97)21039-1.

Van der Kloot Meijburg, H.H., and R.H.J. Ter Meulen. 2001. Developing standards for institutional ethics committees: Lessons from the Netherlands. J Med Ethics 27 (suppl 1): i36-i40.

Varelius, Jukka. 2008. Is ethical expertise possible? Medicine. Health Care and Philosophy 11 (2): 127-132. doi:10.1007/s11019-007-9089-8.

Weidema, F.C., A.C. Molewijk, Guy Widdershoven, and T.A. Abma. 2012. Enacting ethics: Bottom-up involvement in implementing moral case deliberation. Health Care Anal 20 (1): 1-19. 